\title{
Polymer Blocking Distribution and Causes Analysis during Surfactant/Polymer Flooding in Conglomerate Reservoir
}

\author{
Chen Sun and Yiqiang Li
}

\begin{abstract}
Some blocked phenomenon happened since the Surfactant/Polymer (SP) flooding field experiment began in the China Karamay oilfield Qizhong district which is a conglomerate reservoir, for instance, worse flow ability and low liquid production capacity. We carried out a series of flow ability experiments for different SP flooding systems in natural cores with different permeability under reservoir condition. Even more important, We determined the polymer's distribution in cores by nitrogen element calibration using EPMA (Electron probe micro-analyzer). The flowing experiment results showed that the SP flooding system can continue to flow in the district with a permeability above average level by reducing polymer molecular weight and concentration. The district with a permeability under average level should replace SP flooding with water flooding. According to the EPMA results, polymer was mainly distributed in pore edge, clay and fragment abundance area and the pore channels. The retention volume in pore channels was the main factor that affected flow ability. Once the polymer content in the pore channels approached to that in the other two areas which were saturated by polymer during the flooding, the mainstream channels will be blocked by polymer. That's the mechanism for the polymer blocking.
\end{abstract}

Index Terms-Nitrogen element calibration, polymer blocking, SP flooding, microcosmic distribution.

\section{INTRODUCTION}

SP flooding pilot area of Karamay oilfield Qizhong district is a conglomerate reservoir and the average permeability of this area is $93 \times 10^{-3} \mathrm{\mu m}^{2}$. The recovery percent of this reserve is $38.9 \%$ by water flooding and the water cut is $89.6 \%$. The molecular weight (25million) and concentration $(1500 \mathrm{mg} / \mathrm{L})$ of polymer in SP flooding was too high to flow since the SP flooding field experiment began, liquid production capacity of pilot area decreased gradually, and the flow ability of formation became worse. This bad situation hasn 't been remitted after the molecular weight and concentration of polymer dropped to 10 million and $1000 \mathrm{mg} / \mathrm{L}$. According to a preliminary inspection, blocking resulted from the incompatibility between polymer solution of SP flooding and the reservoir [1]-[3]. In order to research the blocking location and the occurrence of polymer in porous media, we inject SP solutions with different compositions in proper order into the natural cores which are from the reservoir. Then we measured some

Manuscript received October 30, 2015; revised February 20, 2016.

The authors are with China University of Petroleum, China (e-mail: 515947931@qq.com, lyq13504598848@163.com). parameters, such as resistance factor and residual resistance factor, and determine the blocking location. The distribution and occurrence of polymer in porous media can be determined by means of EPMA (Electron probe micro-analyzer), and we can analyze the reason of blocking.

\section{EXPERIMENT MATERIAL}

The injection water of this experiment is polluted water and the salinity is $2708 \mathrm{mg} / \mathrm{L}$. Formation water is $\mathrm{NaHCO}_{3}$ type and the salinity is $8245 \mathrm{mg} / \mathrm{L}$. The crude oil used in this experiment is a compound of Qizhong district dehydrated crude and kerosene. Its viscosity is $6 \mathrm{~m} \mathrm{~Pa} \cdot \mathrm{s}$ at $40{ }^{\circ} \mathrm{C}$. Formation temperature: $40{ }^{\circ} \mathrm{C}$. Polymer Type: HPAM; Molecular weight: 10million, 15 million, 25 million. Surfactant: KPS202, Effective content: $10 \%$.

\section{EXPERIMENT EQUIPMENT}

Texas500C spinning drop interfacial tensiometer; BROOKFIELD DV-III Brookfield viscometer; 260D micro-pump produced by ISCO Company; JEOL scanning EPMA.

\section{SP FLOODING PARAMETER}

SP flooding pilot area of Qizhong district chose injection system A at first. After a period of time, the unbalance of injection and production intensified. The pilot area changed the SP flooding formulation into injection system B. But the unbalance of injection and production hasn $t$ been remitted They changed the SP flooding formulation into injection system C. According to the SP flooding injection process in that pilot area, we prepared SP flooding solutions with different molecular weight and concentration and measured their viscosity and IFT (see Table I).

\section{EXPERIMENT PLAN}

Natural cores were chosen representatively to run the experiments on flow ability under the oilfield situation. Injection system A, B and C three slugs were injected in turn when the pressure was steady after injecting previous plug. Finally we started the subsequent water flooding. The resistance factor (Fr) and residual resistance factor (Frr) were calculated with pressure dates that we have gathered. 


\section{RESULT AND ANALYSIS OF EXPERIMENT ON FLOW ABILITY}

According to the experiment plan, we carried out the core sample flow experiments. The following results have been obtained by measuring some parameters, such as inject pressure and injected volume.

TABLE I: VISCOSITY AND IFT OF DIFFERENT SP FLOODING SOLUTION

\begin{tabular}{|c|c|c|c|c|c|c|}
\hline No. & Polymer Molecular weight (million) & Polymer concentration (mg/L) & $\begin{array}{c}\text { Surfactant } \\
\text { concentration } \\
(\%)\end{array}$ & $\begin{array}{c}\text { Viscosity before } \\
\text { shearing } \\
(\mathrm{mPa} \cdot \mathrm{s})\end{array}$ & $\begin{array}{c}\text { Viscosity } \\
\text { after shearing } \\
(\mathrm{mPa} \cdot \mathrm{s})\end{array}$ & $\begin{array}{c}\text { IFT } \\
\left(\mathrm{mN} / \mathrm{m}^{-1}\right)\end{array}$ \\
\hline A & 25 & 1500 & 0.3 & 53.9 & 23.7 & 0.006 \\
\hline B & 15 & 1500 & 0.3 & 28.8 & 12.8 & 0.007 \\
\hline $\mathrm{C}$ & 10 & 1000 & 0.3 & 14.5 & 6.3 & 0.009 \\
\hline
\end{tabular}

TABLE II: EXPERIMENT PlANS ON FlOW ABILITY OF CORES WITH DIFFERENT PERMEABILITY

\begin{tabular}{|c|c|c|c|c|c|c|}
\hline No. & Absolute Permeability $\left(\times 10^{-3} \mu \mathrm{m}^{2}\right)$ & Effective Permeability $\left(\times 10^{-3} \mu \mathrm{m}^{2}\right)$ & & SP Flooding & & Subsequent Water Flooding \\
\hline 1 & 53.3 & 29.6 & & & & \\
\hline 3 & 153.5 & 90.2 & & & & \\
\hline
\end{tabular}

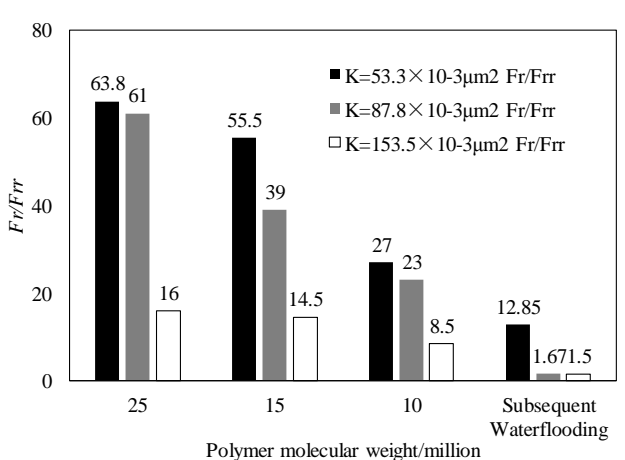

Fig. 1. Fr/Frr in immediate vicinity of wellbore of SP flooding.

As we can see from Fig. 1, SP flooding solutions established a high resistance factor $(\mathrm{Fr}>60)$ in core samples with permeability at $53.3 \times 10^{-3} \mu \mathrm{m}^{2}$ and $87.8 \times 10^{-3} \mu \mathrm{m}^{2}$. In other words, slug A can't flow effectively in those porous media. The SP flooding solution flow in troubles $(\mathrm{Fr}=16)$ in core sample with permeability.

With the decrease of polymer molecular weight and concentration, the resistance factor of core sample with different permeability declined gradually and the difficulty in flowing remitted. After comparing the residual resistance factor, we can find that the residual resistance factor of core samples with permeability at $87.8 \times 10^{-3} \mu \mathrm{m}^{2}$ and $153.5 \times 10^{-3}$ $\mu \mathrm{m}^{2}$ are less than 2 . It means the blocking phenomenon has been remitted effectively. The slug with low polymer molecular weight and concentration was injected after the slug with high polymer molecular weight and concentration. In this injection sequence, the polymer molecule absorbed on the rock surface will desorb from it, the adsorbing capacity of polymer molecule in pore canal will decline and flow difficulty will decrease [4]. On the other hand, the slug with low polymer molecular weight and concentration is able to reduce the internal pressure of cores. It leads to the result that polymer molecules which have been squeezed into the small cores by high pressure released into the pore canals. The Adsorption trapping volume of polymer molecule on rock surface will decrease and the possibility of pore blocking become smaller. Finally, the flow difficulty will be remitted [5].

But the residual resistance factor of the core sample with permeability at $53.3 \times 10-3 \mu \mathrm{m}^{2}$ is 12.85 . It means blocking phenomenon still exist in low permeability layer obviously, even if we have decline the polymer molecular weight and concentration of SP flooding system. The main reason of this phenomenon is the incompatibility between SP flooding system and the reservoir, and it leads to the pore blocked by polymer [6]-[8]. The polymer retention volume in reservoir relates to the porosity and permeability of reservoir. Polymer molecules is much easier to remain in the porous media and result in blocking if its molecular weight is high, pore structure is complex or the permeability is low.

\section{EPMA EXPERIMENT RESULT AND ANALYSIS}

We flaked the pore sample which have been flooded and measured its nitrogen content by using EPMA. The polymer distribution location and content difference in porous media can be speculated by the testing results. There was the acylamino with nitrogen in HPAM. The nitrogen content in porous media and water is extremely low. So we can determine the location and content of HPAM by testing nitrogen content.

We classified the porous media as three different types: 1) Pore edge, 2) clay and fragment abundance area, 3) The mainstream channel. We determine the area that polymer is easy in gathering by measuring the polymer content of those area. Polymer average content of whole sample can be given in this experiment.

\section{A. Experiment Result of Pore Sample with a Permeability at $153.5 \times 10^{-3} \mu^{2}$}

From the Fig. 2, the average nitrogen content of the core sample with a permeability at $153.5 \times 10^{-3} \mu \mathrm{m}^{2}$ is $6.79 \%$. Polymers are mainly distributed in pore edge and clay and fragment abundance area. There was no polymer in mainstream channels according to the experiment result.

\section{B. Experiment Result of Pore Sample with a Permeability at $87.8 \times 10^{-3} \mu^{2}$}

The Fig. 3 shows the average nitrogen content of the core sample with a permeability at $153.5 \times 10^{-3} \mu \mathrm{m}^{2}$ reaches $8.15 \%$. Polymers are mainly distributed in pore edge and clay and fragment abundance area, and there were also some 
polymers distributed in the pore channels.

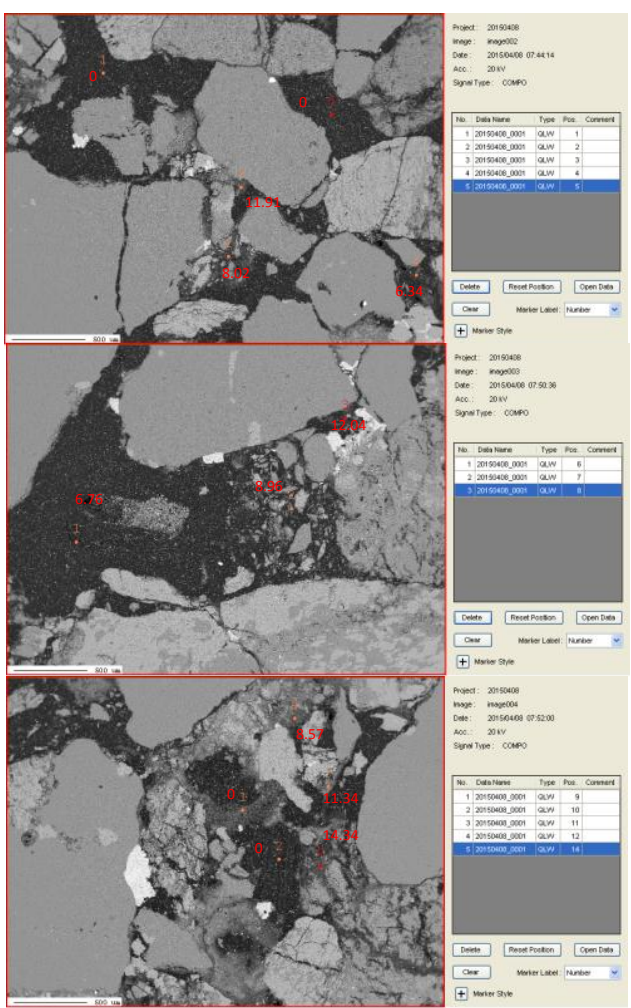

Fig. 2. Nitrogen distribution of core sample with a permeability at $153.5 \times 10^{-3} \mu^{2}$ (number represent nitrogen content of this area).

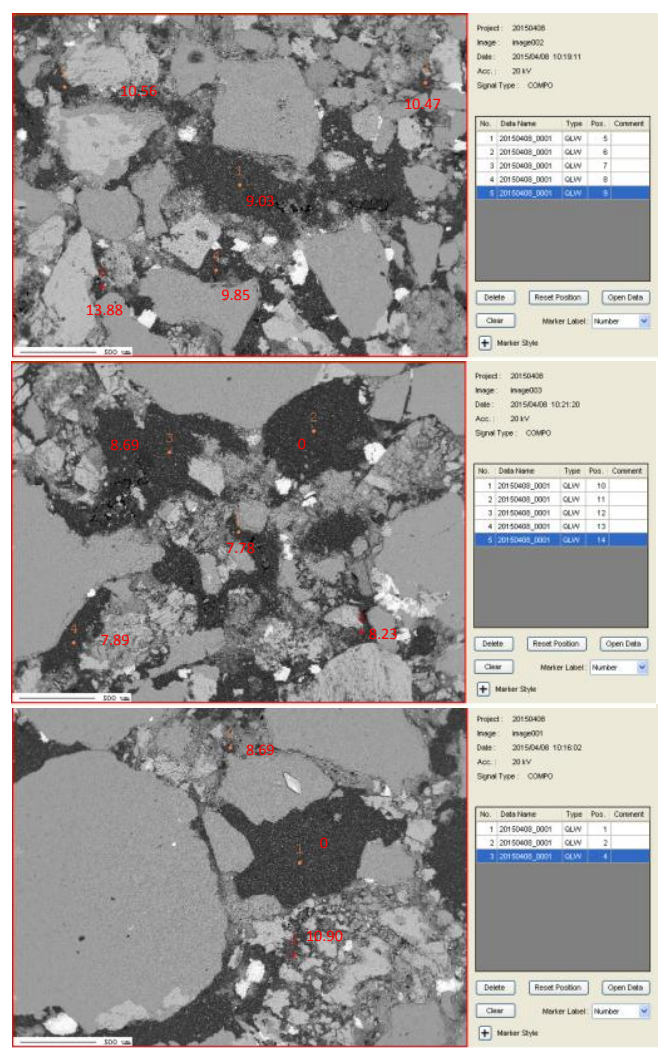

Fig. 3. Nitrogen distribution of core sample with a permeability at $87.8 \times 10^{-3} \mu^{2}$ (number represent nitrogen content of this area).

\section{Experiment Result of Pore Sample with a Permeability at $53.3 \times 10-3 \mu \mathrm{m}^{2}$}

In the Fig. 4, the average nitrogen content of the core sample with a permeability at $53.3 \times 10^{-3} \mu \mathrm{m}^{2}$ reached $9.36 \%$. Polymers were mainly distributed in pore edge and clay and fragment abundance area, and we have detected polymer in almost all pore channels.

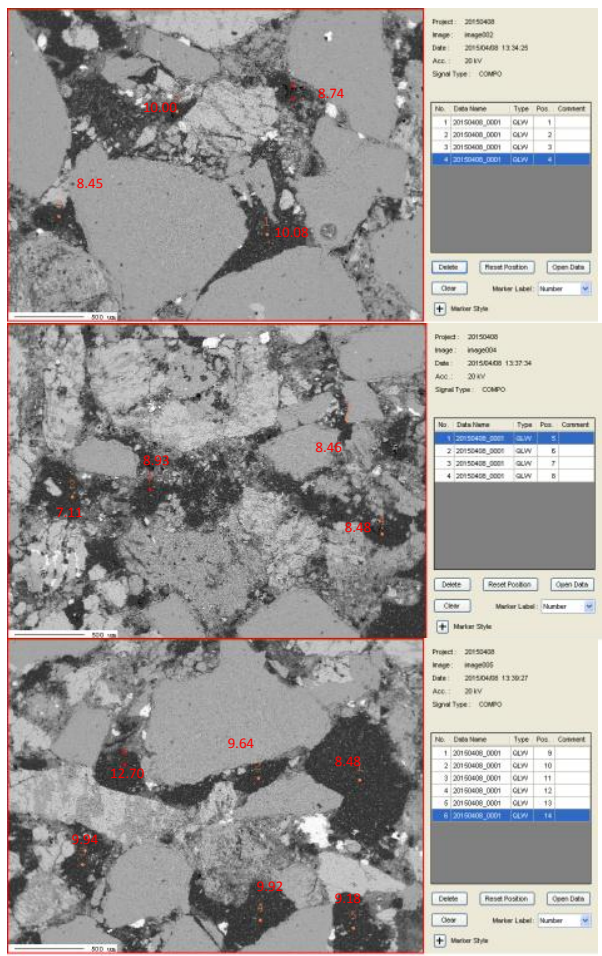

Fig. 4. Nitrogen distribution of core sample with a permeability at $53.3 \times 10^{-3} \mu \mathrm{m}^{2}$ (number represent nitrogen content of this area).

By comparing the experiment results and classifying the dates by types of gathering zone, we got the results in Fig. 5.

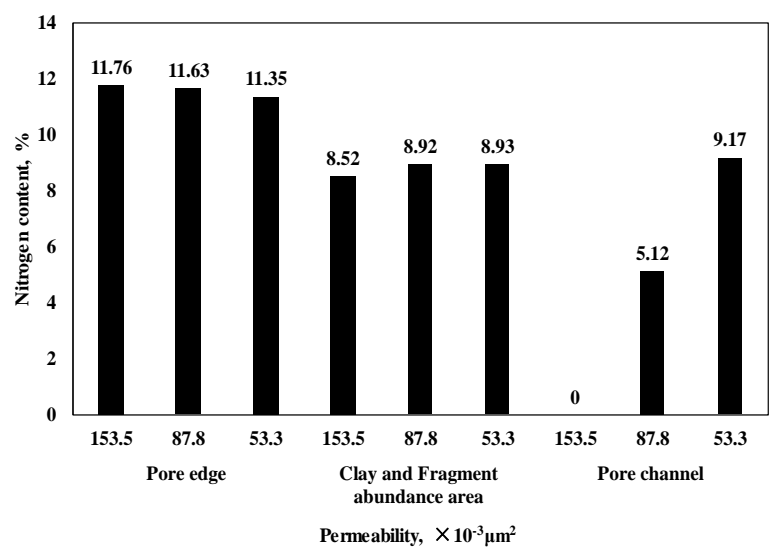

Fig. 5. Nitrogen distribution condition in different area of core samples with different permeability.

Degree of polymer enrichment was similar in pore edge and clay and fragment abundance area in pore samples with different permeability. It meant the absorption of rock particles surface reached balance after polymer solution flooding. This kind of absorption will result in rock physical property worse [9]-[11]. But it doesn`t affect the flow ability of reservoir heavily ( the residual resistance factors of core samples with permeability at $87.8 \times 10^{-3} \mu^{2}$ and $153.5 \times 10^{-3}$ $\mu \mathrm{m}^{2}$ are less than 2). The main factor which affect the flow ability is the polymers gathering in the pore channels. The polymer retention volume increases rapidly with the decrease of permeability (the nitrogen content increased from $0 \%$ to $9.17 \%$ gradually). When the polymer retention 
volume of pore channels approaches the volume of other two areas, the phenomenon that polymer blocking the reservoir will take place (the residual resistance factor of core sample with permeability at $53.3 \times 10-3 \mu \mathrm{m}^{2}$ is 12.85 ).

\section{CONCLUSION}

After a series of injection system adjustment, formation damage of the reservoirs in SP flooding pilot area of Qizhong district with a permeability above average level is relatively $\operatorname{low}(\mathrm{Frr}<2)$. SP flooding experiment can be carried out in those reservoirs, but the polymer molecular weight and concentration must be reduced.

The polymer blocking phenomenon in the reservoirs with a permeability under average level was serious. We suggested the oilfield company to replace SP compound flooding with water flooding on those reservoirs in order to prevent those reservoirs from more serious formation damage.

Polymer in porous media is mainly distribute in: a. pore edge, b. clay and fragment abundance area, c. the pore channel. The absorption in pore edge and clay and fragment abundance area reaches saturation after surfactant-polymer solution flooding. The absorption in pore edge and clay and fragment abundance area will reduce the flow ability of reservoir partly, but it will not lead to serious consequences.

Once polymer distributed in pore channels in abundance, the flow ability of reservoir will be effected directly. With the decrease of reservoir permeability, the polymer retention volume in pore channels increased rapidly. Finally, the mainstream channels will be blocked by polymer. The flow ability of reservoir will be harmed seriously.

\section{ACKNOWLEDGMENTS}

This project is funded by the National Natural Science Foundation of China (No.51374221).

\section{REFERENCES}

[1] Z. Hua, M. Lin, and Z. Dong, "Study of deep profile control and oil displacement technologies with nanoscale polymer microspheres," Journal of Colloid and Interface Science, vol. 4, pp. 67-74, 2014

[2] H. Feng, X. Nie, and G. Xu, "Microscopic mechanisms of oil displacement by polymer solution for conglomerate reservoir," Oilfield Chemistry, vol. 243, pp. 232-237, 2007.

[3] R. Farajzadeh and M. Lotfollahi, "Simultaneous sorption and mechanical entrapment during polymer flow through porous media," presented at the SPE Kuwaiit Oil \& Gas Show and Conference, October 11-14, 2015.
[4] Q. Feng, X. Chen, and G. Zhang, "Experimental and numerical study of gel particles movement and deposition in porous media after polymer flooding," Transp Porous Med, vol. 97, pp. 67-85, 2013.

[5] R. S. Seright, T. Fan, and K. Wavrik, "New insights into polymer rheology in porous media," presented at the 2010 SPE Improved Oil Recovery Symposium held in Tulsa, Oklahoma, USA, 24-28, April 2010.

[6] S. Kudaibergenov, N. Nuraje, and Z. Adilov, "Plugging behavior of gellan in porous saline media," Journal of Applied Polymer Science, 2015 .

[7] J. Wang, Y. Huang, and H. Gu, "Optimization study of injection parameters for weak gel displacement control in conglomerate oil reservoir," Petroleum Geology and Recovery Efficiency, vol. 13, no. 1, pp. 102-104, 2006.

[8] M. A. Malik, M. Y. Wani, M. A. Hashim, and Microemulsion. "Method: A novel route to synthesize organic and inorganic nanomaterials," Arabian Journal of Chemistry, vol. 5, no. 4, pp. 397417, 2012.

[9] J. L. Baez, M. P. Ruiz, and J. Faria, "Stabilization of interfacially active nanohybrids/polymer suspensions and transport through porous media," presented at the Eighteenth SPE Improved Oil Recovery Symposium held in Tulsa, Oklahoma, USA, 14-18 April, 2012.

[10] L. Villamizar, P. Lohateeraparp, and J. Harwell, "Interfacially active SWNT/silica nanohybrid used in enhanced oil recovery," presented at the 2010 SPE Improved Oil Recovery Symposium, Tulsa, Oklahoma, 26-28 April 2010

[11] A. Almohsin, B. Bai, and A. Imqam, "Transport of nanogel through porous media and its resistance to water flow," presented at the SPE Improved Oil Recovery Symposium held in Tulsa, Oklahoma, USA, 12-16 April, 2014.

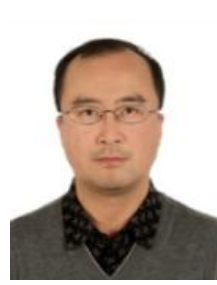

Yiqiang Li was born on January 31, 1972 in Heilongjiang China. He graduated from University of Chinese academy of sciences in 2006. And he received his doctor degree in oil and gas field development. He mainly engaged in enhanced oil recovery research.

$\mathrm{He}$ is vice-president at EOR Institute, China University of Petroleum. He published many papers such as: "Study on matching relation between polymer hydrodynamic characteristic size and pore throat radius of intended block S based on microporous membrane filtration method", "The application of laser confocal method in microscopic oil analysis". At present, his main research area is chemical flooding enhanced oil recovery.

Dr. Li is the editor of "The Open Transport Phenomena Journal".

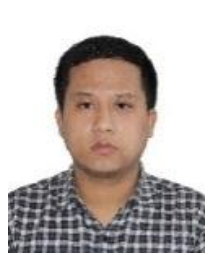

Chen Sun was born on October 12, 1985 in Jiangsu China. He graduated from China Southwest Petroleum University in 2009 and received his master degree in oil and gas field development. He mainly engaged in enhanced oil recovery research.

$\mathrm{He}$ is a science $\mathrm{Ph} . \mathrm{D}$. candidate at China University of Petroleum now, and he used to be the assistant teacher about "petroleum physics". He published some papers such as: "Dispersing effect of resins on asphaltenes in crude oil". At present, his main research area is chemical flooding enhanced oil recovery.

Mr. Sun has taken part in editing the book "Air Foam Flooding Technology and Application". 